\title{
Conception et évaluation de systèmes de culture maraîchers méditerranéens innovants pour gérer les nématodes à galles
}

\author{
Caroline Djian-Caporalino ${ }^{(1)}$, Mireille Navarrete ${ }^{(2)}$, Ariane Fazari ${ }^{(1)}$, Marc Baily-Bechet ${ }^{(1)}$, \\ Nathalie Marteu ${ }^{(1)}$, Arnaud Dufils ${ }^{(2)}$, Marc Tchamitchian ${ }^{(2)}$, Amélie Lefèvre ${ }^{(3)}$, \\ Laure Pares ${ }^{(3)}$, Thierry Mateille ${ }^{(4)}$, Johannes Tavoillot ${ }^{(4)}$, Alain Palloix ${ }^{(5, \$)}$, Anne- \\ Marie Sage-Palloix ${ }^{(5)}$, Hélène Védie ${ }^{(6)}$, Claire Goillon ${ }^{(7)}$, Philippe Castagnone-Sereno ${ }^{(1)}$ \\ (1) INRA, Université Côte d'Azur, CNRS, ISA, 06410 Biot, France. E-mail : caroline.caporalino@inra.fr \\ (2) ECODEVELOPPEMENT, INRA, 84914 Avignon, France. \\ (3) Domaine expérimental Alénya-Roussillon, Univ. Montpellier, INRA, 66200 Alénya, France. \\ (4) CBGP, IRD, CIRAD, INRA, Montpellier SupAgro, Univ. Montpellier, 34988 Montpellier, France. \\ ${ }^{(5)}$ GAFL, INRA, 84140 Montfavet, France. \\ ${ }^{(6)}$ GRAB (Groupe de Recherche en Agriculture Biologique), 84911 Avignon, France. \\ (7) APREL (Assoc iation Provençale de Recherche et d'Expérimentation Légumière), 13210 Saint-Rémy de Provence, \\ France.
}

Reçu le 8 juin 2018, accepté le 18 décembre 2018, mis en ligne le 5 février 2019.

Cet article est distribué suivant les termes et les conditions de la licence CC-BY (http://creativecommons.org/licenses/by/4.0/ deed.fr)

Description du sujet. Une approche système basée sur la co-conception et l'évaluation expérimentale in situ de prototypes de systèmes de culture (SDC) a été mise en œuvre dans le projet INRA «GeDuNem » pour une gestion durable des nématodes à galles (NG) dans les systèmes maraîchers sous abris.

Objectifs. Il s'agissait (i) d'évaluer pendant quatre ans diverses stratégies de culture combinant résistances génétiques et pratiques culturales (rotations culturales incluant des plantes sensibles, résistantes et non-hôtes, gestion de l'interculture avec couvert végétal nématicide ou solarisation) pour réduire les populations de NG dans le sol et augmenter la durabilité des résistances variétales à ces bioagresseurs, (ii) d'étudier leur impact sur les communautés de nématodes rencontrées et (iii) d'évaluer l'acceptabilité des nouveaux SDC par les agriculteurs.

Méthode. Trois prototypes de SDC, co-conçus entre acteurs de la recherche et ceux du développement, ont été comparés à des SDC appliqués classiquement en région méditerranéenne et évalués grâce à des dispositifs complémentaires : (i) expérimentations-système sur trois sites de producteurs du Sud de la France ; (ii) expérimentations analytiques pour approfondir les mécanismes d'action des leviers mobilisés ; (iii) enquêtes pour évaluer l'acceptabilité des prototypes par les agriculteurs. Résultats. Les trois SDC se sont révélés efficaces (90\% de réduction des NG, protection des Solanaceae à résistance partielle, pas d'effet négatif sur les nématodes non phytoparasites) et durables lorsque les conditions d'application et les équilibres biologiques du sol étaient favorables (nématofaune totale diversifiée et abondante). Leur degré d'acceptabilité dépendait du type d'exploitation et de la sensibilité des agriculteurs face à l'innovation.

Conclusions. Ces nouveaux SDC doivent encore être améliorés, en interaction avec les producteurs, tant en termes d'efficacité, par l'introduction de nouveaux leviers agroécologiques, que de cout. Les recherches futures devront aussi s'ouvrir à la gestion plus globale de la santé des sols.

Mots-clés. Nématodes des plantes, protection intégrée, durabilité des résistances, pratiques culturales, expérimentationsystème.

Design and assessment of innovative Mediterranean vegetable cropping systems to manage root-knot nematodes Description of the subject. A system approach based on co-design and experimental field evaluation of cropping systems (CSs), combining technical and varietal innovations, has been implemented for sustainable management of root-knot nematodes $(\mathrm{RKN})$ in Mediterranean sheltered vegetable systems. 
Objectives. Cropping systems combining genetic resistance and cultural practices (crop rotations including susceptible, resistant, and non-host plants; intercropping management with nematicidal cover crops or soil solarization) were assessed over a period of 4 years (i) to reduce RKN populations and increase the durability of varietal resistances, (ii) to study the impact of these systems on soil ecology (plant-parasitic and free-living nematode communities), and (iii) to evaluate their acceptability by farmers.

Method. Three CS prototypes, resulting from a co-design process with research and development stakeholders, were compared with CSs conventionally implemented in the Mediterranean region. The three prototypes were also evaluated using complementary methods: (i) system experiments in three commercial farms in Southern France; (ii) analytical experiments to decipher the mechanisms of action for some [agroecological??] levers; (iii) surveys to evaluate the acceptability of the prototypes by farmers.

Results. All three CSs were found to be effective (90\% RKN decrease, protection of partially resistant Solanaceae, no negative effect on non-phytoparasitic nematodes) and sustainable, when application conditions and soil biological equilibrium were favorable (global soil nematofauna diversified and abundant). The acceptability of the three systems depended on the type of farm where they were implemented and the attitude of the farmers towards innovation.

Conclusions. These three CSs still need to be improved, in terms of their efficiency, in consultation with participating farmers, by introducing new agroecological levers, as well as innovation costs. Future research will also need to open up to a more comprehensive management of soil health.

Keywords. Plant nematodes, integrated pest management, resistance gene durability, agronomic practices, system experiment.

\section{INTRODUCTION}

Les systèmes maraîchers méditerranéens sous abri s'appuient principalement sur des rotations culturales intensives et peu diversifiées qui les exposent particulièrement aux bioagresseurs telluriques. Une enquête a révélé l'importance particulière des nématodes à galles (NG, Meloidogyne spp.), ravageur d'importance mondiale (Jones et al., 2013), dans plus de $40 \%$ des exploitations conventionnelles et en agriculture biologique du Sud-Est de la France (Djian-Caporalino, 2012). Elle souligne l'inquiétude accrue des producteurs vis-à-vis d'espèces de quarantaine qui les obligeraient à une jachère noire des parcelles touchées (Villeneuve et al., 2013). De plus, suite à l'évolution de la législation européenne en matière d'homologation et d'usage des pesticides, de nouveaux modes de production moins dépendants des nématicides doivent être recherchés et développés à large échelle, en s'appuyant sur les principes de la protection intégrée et en introduisant des méthodes de lutte alternatives. Or, prises individuellement, les méthodes contre les bioagresseurs telluriques, qu'elles soient physiques, biologiques, génétiques ou culturales, ont toutes montré leurs limites (Collange et al., 2011).

L'utilisation de variétés ou porte-greffes résistants est une voie en plein essor qui se heurte néanmoins à trois contraintes biologiques majeures :

- le nombre limité d'espèces végétales avec des variétés commercialisées porteuses de gènes de résistance aux NG (seulement tomate et piment en maraîchage),

- l'émergence de populations de NG virulentes capables de contourner la résistance,

- l'inactivité de certains gènes (gène $M i-1$ de la tomate par exemple) lorsque les températures du sol sont supérieures à $30^{\circ} \mathrm{C}$, condition fréquente sous abri en été en zone méditerranéenne.

De plus, l'intégration de ces variétés dans des successions de cultures se heurte à des contraintes sociotechniques, notamment commerciales (Navarrete et al., 2017). Des travaux antérieurs ont montré l'effet bénéfique de stratégies intégrées, associant résistance variétale et autres méthodes de lutte, pour diminuer la quantité d'agents pathogènes et accroitre ainsi la durabilité des gènes de résistance pour le soja contre le nématode Xiphinema americanum et le virus du rabougrissement du soja (Evans et al., 2007), pour le colza contre Leptosphaeria maculans (Brun et al., 2010), ainsi que pour le blé contre Puccinia triticina, Septoria tritici et Pseudocercosporella herpotrichoides (Meynard et al., 2003 ; Loyce et al., 2008).

En maraîchage, des travaux préliminaires, portant sur le contrôle simultané de plusieurs groupes de bioagresseurs telluriques, ont permis la sélection de composantes techniques et agronomiques pouvant être combinées selon les principes agroécologiques (Collange et al., 2014) en suivant une approche système (Reau et al., 2012 ; Havard et al., 2017). La démarche a consisté dans un premier temps à concevoir des systèmes de culture (SDC) innovants, puis à les évaluer via l'expérimentation pluriannuelle et multi-site chez des agriculteurs candidats (Navarrete et al., 2010). Elle s'appuyait sur la complémentarité des connaissances de scientifiques (pathologistes, nématologistes, généticiens et agronomes) et de praticiens (ingénieurs de stations expérimentales régionales, conseillers techniques de chambres d'agriculture). Les prototypes mobilisent plusieurs pratiques destinées à réduire les populations de NG dans le sol (solarisation, engrais vert nématicide ou plante-piège en interculture) combinées à des rotations alternant des cultures commerciales 
hôtes et des variétés résistantes. Ils ont été conçus pour répondre aux contraintes de différents types d'exploitations maraichères sous abri (exploitations diversifiées commercialisant en circuits courts ou plus spécialisées pour les circuits longs). Il s'agissait donc à la fois de trouver des SDC performants, acceptables par une diversité d'agriculteurs et de suivre les possibles contournements de résistance au fil de quatre années de culture.

\section{MATÉRIEL ET MÉTHODE}

Résultant d'un processus de co-conception par des acteurs delarecherche(INRA,IRD)etdu développement (APREL, GRAB, Chambres d'agriculture de la région PACA), trois prototypes de SDC ont été construits : engrais vert biofumigant (sorgho), engrais vert piège et résistant (piment) et solarisation. Leur évaluation a reposé sur des dispositifs complémentaires :

- un réseau d'expérimentations-systèmes sur trois sites de producteurs en agriculture biologique ou conventionnelle du Sud-Est de la France pour évaluer leurs effets sur les NG, mais aussi sur d'autres nématodes (phytoparasites et non phytoparasites) (§ 2.1.),

- des expérimentations analytiques réalisées à l'INRA (ISA et Domaine Expérimental Alénya-Roussillon) pour approfondir les connaissances des mécanismes d'action du sorgho nématicide et du piment-piège résistant aux nématodes à galles et évaluer les effets des SDC sur les rendements en tenant compte des dégâts dus à d'autres bioagresseurs (§ 2.2.\& 2.3.),

- une enquête conduite par l'INRA Écodéveloppement pour évaluer la faisabilité technique des prototypes et leur acceptabilité par les agriculteurs et repérer des pistes d'amélioration (§ 2.4.).

\subsection{SDC testés chez des maraîchers}

Description des prototypes de SDC (Tableau 1). Les prototypes reposaient sur des cultures de tomate et piment portant des gènes de résistance aux NG. Les tomates résistantes $M i-1.2$ étaient des variétés

Tableau 1. Les trois prototypes de systèmes de culture (SDC) étudiés pour contrôler les nématodes à galles (NG) - The three cropping systems (SDC) to control root-knot nematodes (NG) (Djian-Caporalino et al., 2015 ; Navarrete et al., 2017).

\begin{tabular}{|c|c|c|c|}
\hline Prototypes de SDC & Type d'exploitation visé & $\begin{array}{l}\text { Voies } \\
\text { d'action }{ }^{1}\end{array}$ & $\begin{array}{l}\text { Degré } \\
\text { d'innovation² }\end{array}$ \\
\hline
\end{tabular}

S1 : engrais vert nématicide en

$1+3 \quad$ Substitution

été une année sur deux (sorgho biofumigant à haute teneur en dhurrine $^{3}$, avec une durée de culture plus courte que le sorgho standard pour maximiser la production de dhurrine et stopper le cycle des NG) ; maintien des cultures classiques hôtes des NG dans la succession

S2 : engrais vert avec une espècepiège des NG (piment combinant deux gènes de résistance) en été

Peu diversifiée, commercialisation en circuit long, avec cultures d'été courtes (arrêt mi-juillet) pour introduire des engrais vert en été une année sur deux ; maintien des cultures classiques hôtes des NG dans la succession

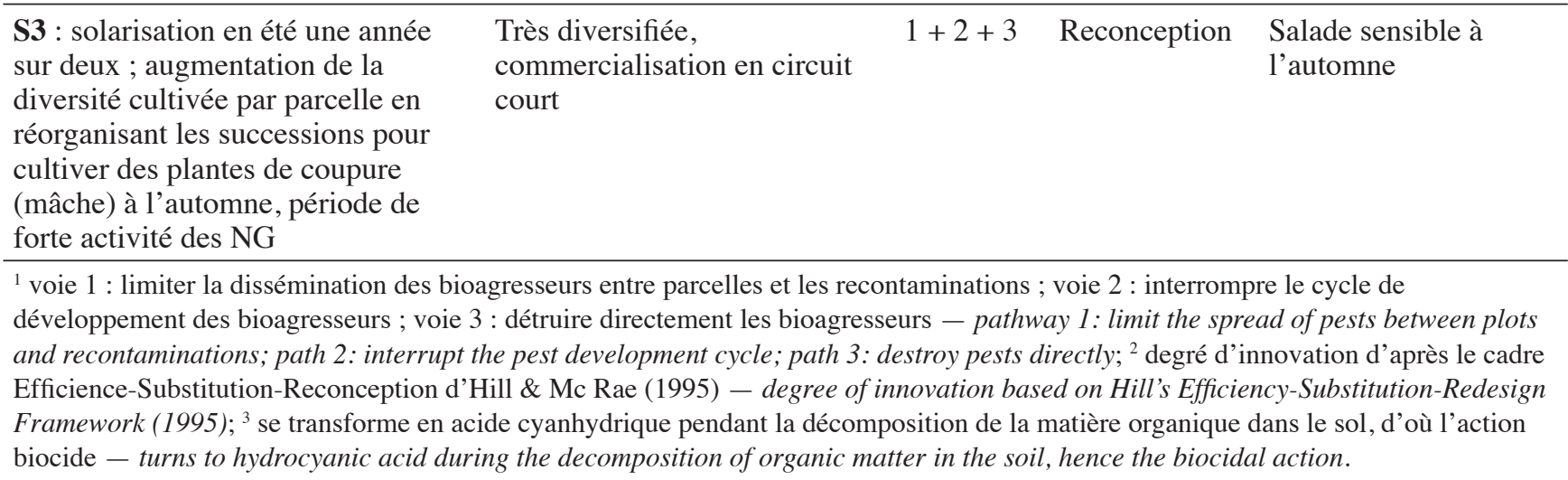

Engrais vert sorgho standard classiquement utilisé par les maraîchers (Sudan grass variété 'Piper') 
commerciales portant le gène de résistance $M i-1.2$ qui contrôle les principales espèces de Meloidogyne de la zone méditerranéenne $(M$. incognita, $M$. arenaria, M.javanica). Faute de disposer de variétés homologuées de piment avec des gènes de résistance aux NG, des piments (Capsicum annum) résistants $M e 3-D L L$ développés à l'INRA GAFL ont été utilisés comme porte-greffes de variétés commerciales. Ces porte-greffes sont issus d'un rétrocroisement de la lignée HD149 (portant le gène majeur Me3 à large spectre qui contrôle les trois espèces de NG) par la variété Doux Long des Landes (DLL, très sensible aux mêmes espèces de Meloidogyne). Ces deux gènes peuvent être contournés par des populations virulentes de Meloidogyne (Castagnone-Sereno, 2002 ; Barbary et al., 2014), ce qui permet de vérifier jusqu'à quel point les prototypes de SDC les protègent.

L'objectif du système $\mathrm{S} 1$, sur une parcelle de $680 \mathrm{~m}^{2}$ naturellement infestée par M. incognita à Lambesc (13), était d'évaluer l'effet d'un engrais vert d'été (sorgho) ayant un potentiel nématicide par effet biofumigant après enfouissement dans le sol. L'engrais vert utilisé était la variété '270911', riche en dhurrine (précurseur de cyanure d'hydrogène), hybride trois voies issu du croisement [Sorgho x Sudan grass], semé à $70 \mathrm{~kg} \cdot \mathrm{ha}^{-1}$ et en cours d'inscription au catalogue CTPS. Le sorgho standard était un Sudan grass variété 'Piper' classiquement utilisé par les maraîchers, semé à $50 \mathrm{~kg} \cdot \mathrm{ha}^{-1}$. Les sorghos étaient broyés et enfouis dans les 10 premiers centimètres du sol un mois après leur semis.

L'objectif du système S2, sur une parcelle de $250 \mathrm{~m}^{2}$ naturellement infestée par M. arenaria à Six-Fours (83), était d'évaluer l'effet d'un engrais vert d'été (piment résistant hybride $\mathrm{Me} 1 / \mathrm{Me} 3$ semé à 12 plants $\cdot \mathrm{m}^{-2}$ ) à effet plante-piège, issu du croisement entre HD149 (Me3) et HD330 (Me1). Mel est un gène majeur à large spectre qui contrôle les trois principales espèces de Meloidogyne. Il a été déjà montré que ces résistances pyramidées $M e 1 / M e 3$ n'étaient pas contournables et que ces piments pouvaient être utilisés comme plantes-pièges pour réduire significativement les niveaux de populations de Meloidogyne dans le sol (Djian-Caporalino et al., 2014). Le sorgho standard était un Sudan grass classique variété 'Piper' semé à $50 \mathrm{~kg} \cdot \mathrm{ha}^{-1}$.

L'objectif du système S3, sur une parcelle de $480 \mathrm{~m}^{2}$ naturellement infestée par $M$. incognita et $M$. arenaria à Marguerittes (30), était d'évaluer l'effet de la solarisation bisannuelle et de la substitution d'une salade sensible par une culture de coupure à l'automne (mâche, non hôte des NG).

Chacun des prototypes a été évalué pendant quatre ans (2012-2015) sur chaque parcelle divisée en deux, l'une pour le prototype, l'autre pour un système témoin correspondant au SDC classiquement pratiqué dans la région. L'évaluation a porté sur l'impact des stratégies sur les populations de NG du sol, sur la protection des cultures sensibles et résistantes de la succession et sur l'écologie du sol (autres nématodes phytoparasites et non phytoparasites, indicateurs de la santé des sols d'après Yeates, 2003).

Analyses des NG sur cultures sensibles et résistantes. L'échantillonnage a été adapté aux configurations spatiales des cultures (en plein ou en rangs) pour suivre l'hétérogénéité des attaques de nématodes. Des paramètres biologiques caractérisant la multiplication des NG sur les cultures testées et l'état infectieux du sol ont été analysés.

Indices de galles sur les cultures (IG). Les IG sur système racinaire ont été déterminés sur 30 à 40 plantes par $1 / 2$ parcelle en fin de culture et évalués sur une échelle de 1 à 10 selon le système de notation de Zeck (1971).

Taux d'infestation du sol (IS). Des échantillons de $1 \mathrm{~kg}$ de sol ont été prélevés après chaque culture dans chaque $1 / 2$ parcelle en huit points fixes et déposés chacun dans un pot contenant un plant de tomate sensible 'Saint-Pierre'. Deux mois plus tard, les racines étaient nettoyées et immergées pendant $10 \mathrm{~min}$ dans une solution d'éosine $\left(0,1 \mathrm{~g} \cdot \mathrm{l}^{-1} \mathrm{~d}\right.$ 'eau $)$ qui colore spécifiquement les masses d'œufs (MO) (Roberts et al., 1990). Le nombre de MO était compté pour chaque plante et la moyenne calculée pour chaque $1 / 2$ parcelle. Le nombre de juvéniles par $\mathrm{dm}^{3}$ de sol était également analysé selon la procédure utilisée pour les communautés de nématodes ci-après.

Les données ont été soumises à une analyse de variance unidirectionnelle (ANOVA) (R Development Core Team, 2011). Les tests de Wilcoxon-MannWhitney ont été utilisés pour chaque comparaison par paire, les valeurs moyennes et les erreurs standards étant utilisées pour comparer les SDC avec le contrôle pour chaque date.

Caractérisation des communautés de nématodes sur les SDC testés chez des maraîchers. Des analyses nématologiques concernant les espèces de nématodes phytoparasites (NPP) et les espèces non phytoparasites (NNP), saprophages, étaient réalisées sur les mêmes points que ceux analysés pour les IS. Les nématodes étaient extraits du sol par élutriation de Seinhorst (1962) (adaptée de ISO_23611-4) puis identifiés et énumérés (nombre de nématodes $\cdot \mathrm{dm}^{-3} \mathrm{de}$ sol), à l'échelle de la famille ou du genre pour les NPP et sans caractérisation taxonomique pour les NNP. Ces notations permettaient d'évaluer les effets des SDC sur l'évolution spatiotemporelle des patrons de communautés et sur la santé des sols (espèces non parasites). 


\section{2. Évaluation agronomique des SDC en station expérimentale}

Les systèmes $\mathrm{S} 1$ et $\mathrm{S} 2$ ont été également conduits dans deux tunnels de $320 \mathrm{~m}^{2}$ indemnes de $\mathrm{NG}$, sur la station expérimentale INRA d'Alénya, en sol limono-sableux (1,7 \% matière organique), afin de recueillir des mesures agronomiques plus précises qu'en parcelles de producteur et d'améliorer les itinéraires techniques. Les sorghos standard 'Piper' ou biofumigant '270911' ont été semés en mai sur une $1 / 2$ parcelle chacun, aux mêmes densités que celles réalisées dans les autres sites expérimentaux, puis broyés et enfouis 52 jours après semis dans les 10 premiers centimètres du sol. Les piments hybrides résistants $\mathrm{Mel} / \mathrm{Me} 3$ cultivés comme engrais vert ont été plantés à une densité de 12 plants $\cdot \mathrm{m}^{-2}$, puis broyés et enfouis 73 jours après semis. Pour chaque modalité, la biomasse produite en fin de culture a été évaluée sur quatre parcelles élémentaires d' $1 \mathrm{~m}^{2}$.

Dans le système S2, la performance du piment hybride résistant $\mathrm{Me} 1 / \mathrm{Me} 3$ utilisé comme plante piège des NG dépend essentiellement de la capacité de son système racinaire à explorer le volume de sol sur lequel se trouvent les NG, afin de maximiser leur piégeage. C'est pourquoi la dynamique d'exploration racinaire a été estimée par l'ouverture de fosses (largeur $1,50 \mathrm{~m} \times$ profondeur $0,60 \mathrm{~m}$ ) au pied d'un lot de six plants successifs à quatre stades du développement du piment. Puis, en appliquant une grille comportant des carreaux de $2 \mathrm{~cm}$ de côté sur le profil de sol, le nombre de racines visibles dans chaque carreau a été dénombré.

\section{3. Étude des mécanismes d'action des sorghos en conditions contrôlées}

Étude de la qualité d'hôte des sorghos. Dans une première expérimentation, les deux sorghos 'Piper' et '270911' ont été comparés pour leur sensibilité à M. incognita. La tomate sensible 'Saint-Pierre' a été utilisée comme témoin. Dix graines de chaque variété ont été cultivées individuellement dans des pots de $400 \mathrm{ml}$ contenant un sol sablo-limoneux stérilisé à la vapeur et maintenu dans des chambres de culture à $24 \pm 2{ }^{\circ} \mathrm{C}$. Quatre semaines après semis, 400, 800 ou 6000 juvéniles (J2) de M. incognita ont été inoculés par pot. Six semaines après inoculation, le nombre de $\mathrm{MO}$ a été déterminé après coloration à l'éosine. Pour une inoculation jusqu'à $800 \mathrm{~J} 2$, les plantes étaient considérées sensibles si $\mathrm{MO}>100$, non hôte si $\mathrm{MO}=0$ et mauvais hôte si $1<\mathrm{MO}<100$. L'inoculation à $6000 \mathrm{~J} 2$ était réalisée pour vérifier si la réduction du taux de multiplication des nématodes sur sorgho comparativement à une tomate sensible était robuste, même en cas de très forte infestation. Les données étaient évaluées dans un test global de
Kruskal-Wallis suivi de tests de Wilcoxon par paires post hoc avec correction de Benjamini-Hochberg pour des tests multiples, avec un seuil de $p=0,05$. Après observation, les mêmes racines ont été colorées à la fuchsine acide (Byrd et al., 1983) pour réaliser des observations histologiques.

Effets du type de sol, du temps de culture et du temps de biofumigation. Une expérimentation multifactorielle en serre a également été menée pour examiner les effets de piège et de biofumigation des deux variétés de sorgho dans trois types de sols: sableux (a : $82 \%$ sable, $9 \%$ limon, $4 \%$ argile, $1,6 \%$ matière organique), argileux (b : $21 \%$ sable, $24 \%$ limon, $33 \%$ argile, $3,9 \%$ matière organique) et sablolimoneux (c : $53 \%$ sable, $22 \%$ limon, $12 \%$ argile, $3,3 \%$ matière organique). Meloidogyne incognita était inoculé à la dose de $1000 \mathrm{~J} 2 \cdot \mathrm{kg}^{-1}$ sol dans des pots de 121 avec huit répétitions par modalité expérimentée. Les variétés '270911' et 'Piper' ont été semées à une densité équivalente de $30 \mathrm{~kg} \cdot$ ha $^{-1}$ et cultivées pendant un ou deux mois en sol sableux (a) ou argileux (b), puis broyées et incorporées dans le sol et maintenues en conditions anaérobies avec un film imperméable (VIF). Les effets de la biofumigation sur les NG ont été examinés 10 jours après l'incorporation des plants de sorghos dans le sol. Pour évaluer l'effet du temps de biofumigation, le sorgho a été cultivé dans un sol sablo-limoneux (c) pendant un mois, incorporé dans le sol, irrigué, bâché avec du VIF et examiné à 10 ou 30 jours. L'IS a été évalué sur un échantillon de sol de chaque pot, à trois stades : avant de semer les graines de sorgho, après la période de croissance (un ou deux mois) et après biofumigation (10 ou 30 jours). Une ANOVA multifactorielle avec toutes les interactions a été effectuée sur les moyennes des différences entre IS au moment considéré et au début de l'expérience. Deux analyses ont été effectuées, avant et après biofumigation (avec facteurs temps $\mathrm{x}$ sol $\mathrm{x}$ sorgho, $2 \mathrm{x}$ $3 \times 2$ ).

\subsection{Enquêtes sur l'acceptabilité des prototypes}

Des enquêtes ont été réalisées en 2012 et 2014 pour évaluer comment des maraîchers de la zone d'étude percevaient les trois prototypes expérimentés, les combinaisons de pratiques qui leur semblaient réalisables (techniquement et commercialement) et à quelles conditions ils seraient prêts à les utiliser. L'hypothèse testée était que l'acceptabilité de chaque prototype dépendait de sa compatibilité avec le type d'exploitation, mais aussi de l'intérêt que l'agriculteur portait aux pratiques agroécologiques et de sa sensibilité à l'innovation. L'échantillon comportait 28 maraîchers de deux départements (Vaucluse et Bouches-du-Rhône) confrontés au problème des NG 
sur leur exploitation et produisant en agriculture biologique ou conventionnelle. L'échantillon couvrait une diversité en termes de surface d'exploitation, de degré de diversification dans les successions de cultures et de modes de commercialisation (circuits courts ou longs) (Chapuis, 2012 ; Furnion, 2014). Après avoir caractérisé le fonctionnement de chaque exploitation (i.e. type d'agriculture, circuits de vente, diversification des cultures), les pratiques utilisées et la sensibilité des agriculteurs face au changement technique, l'enquête consistait à leur faire comparer leurs propres calendriers de culture à ceux des systèmes $\mathrm{S} 1, \mathrm{~S} 2$ et $\mathrm{S} 3$, et à leur faire expliciter s'ils accepteraient de mettre en place ces systèmes et les difficultés éventuelles que cela poserait (Furnion, 2014).

\section{RÉSULTATS}

\subsection{Prototype S1, basé sur un engrais vert sorgho nématicide en été}

Sur le site de Lambesc, les deux sorghos 'Piper' et '270911' ont fortement diminué l'abondance des NG dans le sol, de $95 \%$ par rapport au taux initial en 2012 et de $73 \%$ après plantation de 'Piper' à $82 \%$ après plantation de '270911' en 2014, sans différence significative entre les deux types de sorgho. Par la suite, ces populations sont restées faibles, en dessous du taux initial, après des cultures d'hiver très sensibles (blette ou laitue). Les cultures de piment à résistance contournable cultivées en été ont été protégées par cette réduction de l'IS (aucun contournement de résistance par d'éventuelles populations virulentes n'a été constaté). Les deux cultures d'été sensibles (melon) ont présenté une infestation modérée $(\mathrm{IG}<4)$ mais ont remultiplié les NG. Néanmoins, au cours des quatre années d'expérimentation, l'alternance d'engrais vert sorgho et de cultures partiellement résistantes a permis une diminution de la population de NG de 75 à $87 \%$ par rapport aux niveaux initiaux en fonction de la parcelle de sorgho, sans différence significative entre les parcelles.

Sur ce site, une grande diversité des communautés de nématodes a été observée (Figure 1a). Les familles de NPP détectés étaient : Meloidogynidae, Telotylenchidae, Tylenchidae, Hoplolaimidae, Longidoridae, Paratylenchidae, Criconematidae, Pratylenchidae et Anguinidae. Les quatre premières familles citées étaient les plus abondantes $(>1 \%)$. Les Telotylenchidae se sont multipliés suite aux sorghos, puis la population s'est maintenue, quelle que soit la culture mise en place. Les populations des autres NPP se sont maintenues à des niveaux faibles et n'ont pas été impactées par la rotation engrais vert -
Solanaceae résistantes. Les populations de NNP se sont multipliées tout au long de l'expérimentation et étaient 5,5 fois plus importantes en fin d'essai.

Pour comprendre la diminution des NG dans le sol aussi bien après le sorgho '270911' riche en dhurrine qu'après le sorgho 'Piper' qui était initialement considéré comme témoin, le mode d'action de ces variétés a été étudié en conditions contrôlées. Les deux variétés se sont révélées toutes deux mauvais-hôtes de $M$. incognita $(\mathrm{MO}<100$ ) (Figure 2). Cet effet s'est révélé robuste puisque le taux de multiplication des nématodes sur les deux sorghos était réduit de plus de $85 \%$ par rapport à celui obtenu sur tomate, même avec une inoculation très forte de $6000 \mathrm{~J} 2 \cdot$ plant $^{-1}$. Les galles induites par $M$. incognita sur les racines et les MO produites sur les deux sorghos étaient beaucoup plus petites que celles observées sur tomate. De plus, ces MO se retrouvaient souvent à l'intérieur des racines de sorgho, alors que celles sur racines de tomate étaient toujours à l'extérieur de la galle.

L'expérimentation en containers en serre a montré qu'après un mois de culture, le nombre de nématodes diminuait fortement dans les trois sols pour les deux variétés de sorgho (Figure 3). Par contre, le processus s'inversait après deux mois de culture : une ANOVA multifactorielle sur des données avant biofumigation ( 2 durées de culture $\times 3$ types de sol $\times 2$ variétés de sorgho) a montré une forte augmentation du nombre de MO $\left(p<10^{-11}\right)$ au bout de deux mois de culture par rapport à un mois, l'effet étant plus marqué en sol argileux qu'en sol sableux (Tableau 2). Aucune différence entre les deux variétés de sorgho n'était détectable. En répétant la même analyse après 10 jours de biofumigation, on reproduisait les mêmes résultats.

Ainsi, les deux variétés de sorgho sont capables de multiplier les nématodes dès qu'elles restent en place suffisamment longtemps pour achever le cycle de développement des nématodes (5-6 semaines à $25^{\circ} \mathrm{C}$ ) et 10 jours de biofumigation ne compensent pas l'augmentation du nombre de MO due aux deux mois de culture.

Dans les sols sablo-limoneux après un mois de culture, 30 jours de biofumigation étaient légèrement plus efficaces que 10 jours de biofumigation, entrainant la réduction presque complète de l'IS dans certains pots.

En conclusion, sur un sol avec une grande diversité de nématodes, le prototype $\mathrm{S} 1$ à base d'engrais vert nématicide en été une année sur deux (sorgho biofumigant à haute teneur en dhurrine ou sorgho standard avec une durée de culture courte en été pour maximiser la production de dhurrine et stopper le cycle des NG) permet un contrôle satisfaisant des nématodes à galles. 

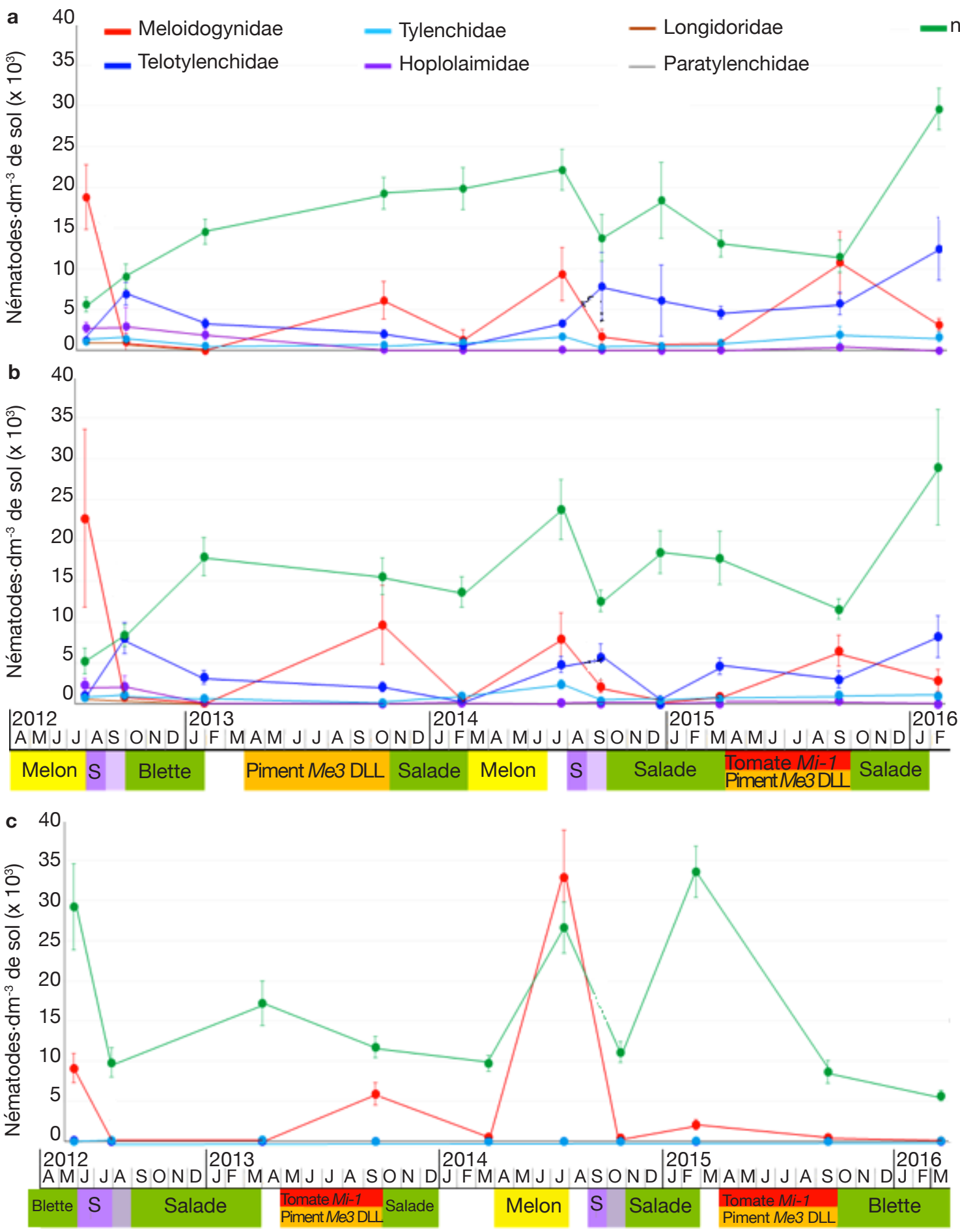

Figure 1. Effet du système de culture alternant sorgho en engrais vert et Solanaceae partiellement résistant aux nématodes à galles en été sur la cinétique des populations de Meloidogyne et de la nématofaune globale du sol : moyennes de 8 répétitions \pm erreur standard - Effect of cropping systems alternating sorghum green manure and Solanaceae with low resistance to rootknot nematodes in summer on the kinetics of Meloidogyne populations and global soil nematofauna: means $(n=8) \pm$ standard error.

a \& b : site de Lambesc - Lambesc site ; c : site de Six-Fours - Six-Fours site; S : Sorgho '270911' (a) ou 'Piper' (b \& c) - Sorghum '270911' (a) or 'Piper' ( $\boldsymbol{b} \& \boldsymbol{c}$ ); piment résistant (Me3 DLL) : différentes variétés de piments greffés sur un porte-greffe piment résistant portant le gène Me 3 dans le fond génétique sensible Doux Long des Landes - different varieties of peppers grafted on a chilli rootstock carrying the Me3 gene in the susceptible genetic background Doux Long des Landes ; tomate résistante Mi-1 : différentes variétés de tomates résistantes portant le gène Mi-1 (non actif à haute température) - different tomato varieties carrying the Mi-1 gene (non-active at high temperature). 
Inoculation avec $400 \mathrm{~J} 2 \cdot$ plant $^{-1}$

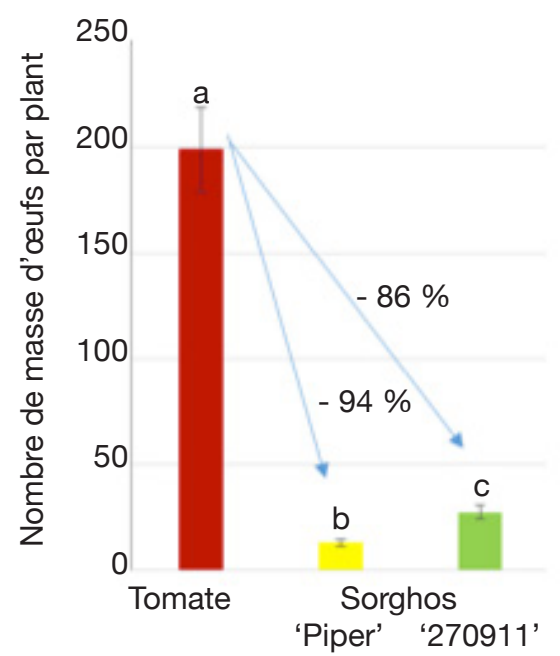

Inoculation avec $800 \mathrm{~J} 2 \cdot$ plant $^{-1}$

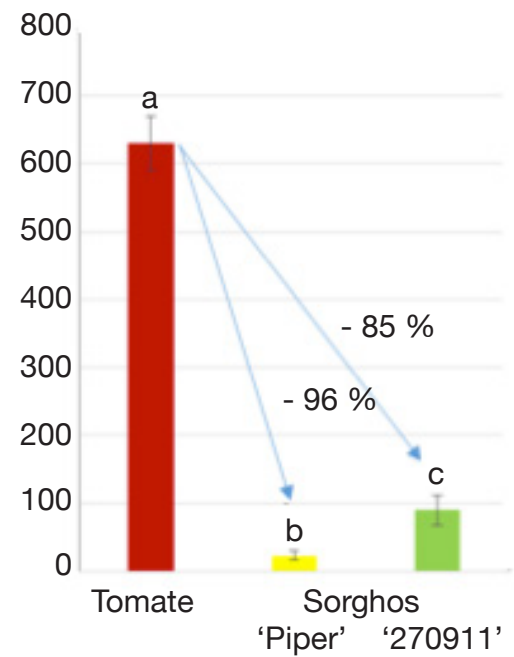

Inoculation avec $6000 \mathrm{~J} 2 \cdot$ plant $^{-1}$

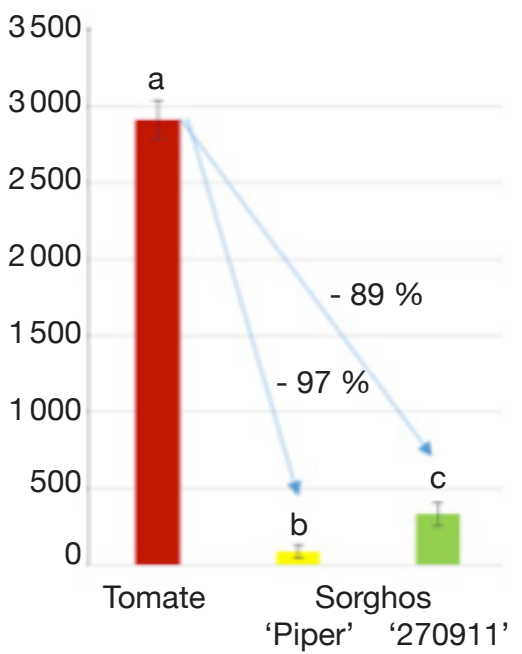

Figure 2. Sensibilité des variétés de sorghos 'Piper' et '270911' comparativement à la tomate vis-à-vis du nématode à galles Meloidogyne incognita exprimée en nombre de masse d'œufs par plant six semaines après inoculation en enceintes confinées climatisées $\left(24^{\circ} \mathrm{C}\right)$ : les moyennes de 10 répétitions \pm erreur standard suivies de lettres différentes sont significativement différentes $(p<0,05)$ - Mean number of egg-masses per plant counted on sorghum 'Piper' and '270911' and on tomato (as a control) maintained in a $24^{\circ} \mathrm{C}$-controlled-climate growth chamber after inoculation with juveniles of Meloidogyne incognita: means $(n=10) \pm$ standard deviation followed by different letters indicate significant differences $(\mathrm{p}<0.05)$.
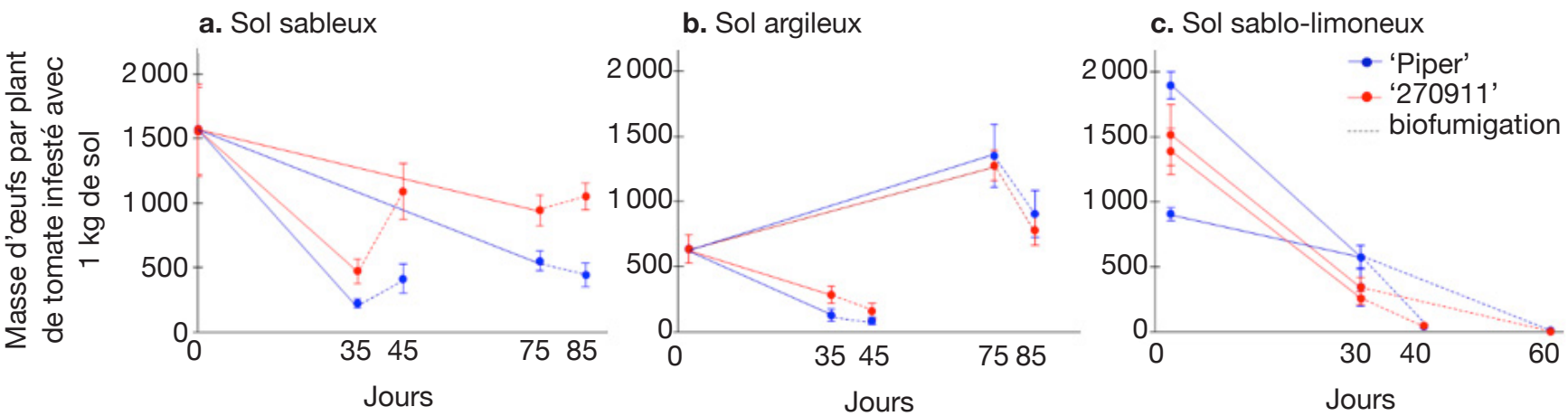

Figure 3. Évolution du potentiel d'infection d'un sol très infesté par Meloidogyne incognita après différents temps de culture des sorghos 'Piper' et '270911' et différents temps de biofumigation, exprimé par le nombre de masse d'œufs sur des plants de tomates sensibles maintenus pendant six semaines en serre dans des pots remplis de $1 \mathrm{~kg}$ de sol rhizosphérique échantillonné : moyennes de 8 répétitions \pm erreur standard. Une ANOVA multifactorielle a été effectuée sur les moyennes avant et après biofumigation (temps x sol x sorgho, c'est-à-dire $2 \times 3 \times 2$ ). Dans les sols sableux (a) et argileux (b), les deux sorghos ont été cultivés pendant un ou deux mois, enterrés, irrigués, bâchés avec du du film imperméable (VIF) pendant 10 jours. Dans le sol sablo-limoneux (c), les deux sorghos ont été cultivés pendant un mois, enterrés, irrigués, bâchés avec du VIF pendant 10 ou 30 jours. Les lignes pointillées indiquent les effets biofumigants - Changes over time in root-knot nematodes soil infection potential with 'Piper' and '270911' in greenhouse experiments, as expressed by the number of egg masses on susceptible tomato plants maintained for six weeks in pots filled with $1 \mathrm{~kg}$ rhizosphere soil sampled from each pot: means $(n=8) \pm$ standard deviation. A multifactorial ANOVA was done on the mean SIP data before and after biofumigation (time $x$ soil $x$ sorgho type, i.e. $2 \times 3 \times 2$ ). In sandy soil (a) and clayey soil (b), both sorghum were grown for one or two months, buried, irrigated, tarped with VIF during 10 days. In sandy-loamy soil (c), both sorghum were grown for one month, buried, irrigated, tarped with VIF during 10 or 30 days. Dotted lines indicate biofumigant effects.

\subsection{Prototype $S 2$, basé sur un engrais vert avec un piment-piège des NG en été}

Sur le site de Six-Fours, partant d'une infestation deux fois moins importante par rapport au site S1 de Lambesc, le prototype a permis plus de $99 \%$ de réduction des populations de Meloidogyne spp., comme le sorgho 'Piper' témoin (Figure 4). Les cultures d'été de tomates ou piments à résistance contournable ont été protégées par cette réduction de l'IS. Les 
Tableau 2. ANOVA multifactorielle sur les moyennes des différences entre taux d'infestation du sol au début de l'expérience et au moment considéré - ANOVA of soil infection rate data before and after biofumigation.

\begin{tabular}{|c|c|c|c|c|c|c|}
\hline & \multicolumn{3}{|c|}{ Avant biofumigation } & \multicolumn{3}{|c|}{ Après biofumigation } \\
\hline & dl & SC & $p$ & dl & SC & $p$ \\
\hline Temps & 1 & 27572673 & $<10^{-11}$ & 1 & 2220990 & $<10^{-4}$ \\
\hline Sol & 2 & 9309191 & $<10^{-15}$ & 2 & 11691741 & $<10^{-14}$ \\
\hline Variété de sorgho & 1 & 40747 & 0,590 & 1 & 295017 & 0,09 \\
\hline Temps*Sol & 1 & 1867127 & $<10^{-3}$ & 1 & 1968328 & $<10^{-4}$ \\
\hline Temps*Sorgho & 1 & 9350 & 0,790 & 1 & 67002 & 0,42 \\
\hline Sol*Sorgho & 2 & 1262920 & 0,014 & 2 & 4202318 & $<10^{-6}$ \\
\hline Temps*Sol*Sorgho & 1 & 138751 & 0,320 & 1 & 14354 & 0,70 \\
\hline Résidus & 83 & 11648935 & & 67 & 6847038 & \\
\hline
\end{tabular}

$\mathrm{dl}$ : degrés de liberté - degrees of freedom; SC : somme des carrés - sum of squares ; $p$ : valeur associée à la variable considérée - value associated to the variable considered.

cultures d'hiver (salade) ont été très peu attaquées. Cependant, la culture sensible (melon) a remultiplié rapidement les NG dans le sol. Le système S2 n'a eu aucune influence sur les autres NPP qui étaient rares (Tylenchidae, Hoplolaimidae, Criconematidae, Pratylenchidae, Telotylenchidae et Paratylenchidae) et très peu abondants (Figure 1b). Les engrais verts ont significativement diminué les populations de NNP, qui n'ont ensuite augmenté qu'au cours de la culture de melon, leur abondance fluctuant avec la même ampleur que celle des Meloidogyne.

L'expérimentation complémentaire conduite en station expérimentale à Alénya montre que pour une densité de plantation du piment de 12 plants $\cdot \mathrm{m}^{-2}$, au bout de trois mois de culture, $80 \%$ du volume de sol est occupé par les racines dans les 30 premiers centimètres qui représentent la zone principale du développement du système racinaire des cultures maraîchères et celle de forte présence des NG (Figure 5). La densité racinaire est plus limitée en profondeur (30-40\%). L'exploration racinaire des cultures de piment commerciales (densité de 2,5 plants. $\mathrm{m}^{-2}$ ) est beaucoup plus faible, satisfaisante sur le rang mais très insuffisante dans les inter-rangs pour espérer un piégeage suffisant et donc un effet assainissant du sol (données non illustrées). Une densité intermédiaire de 9 plants $\cdot \mathrm{m}^{-2}$ a permis

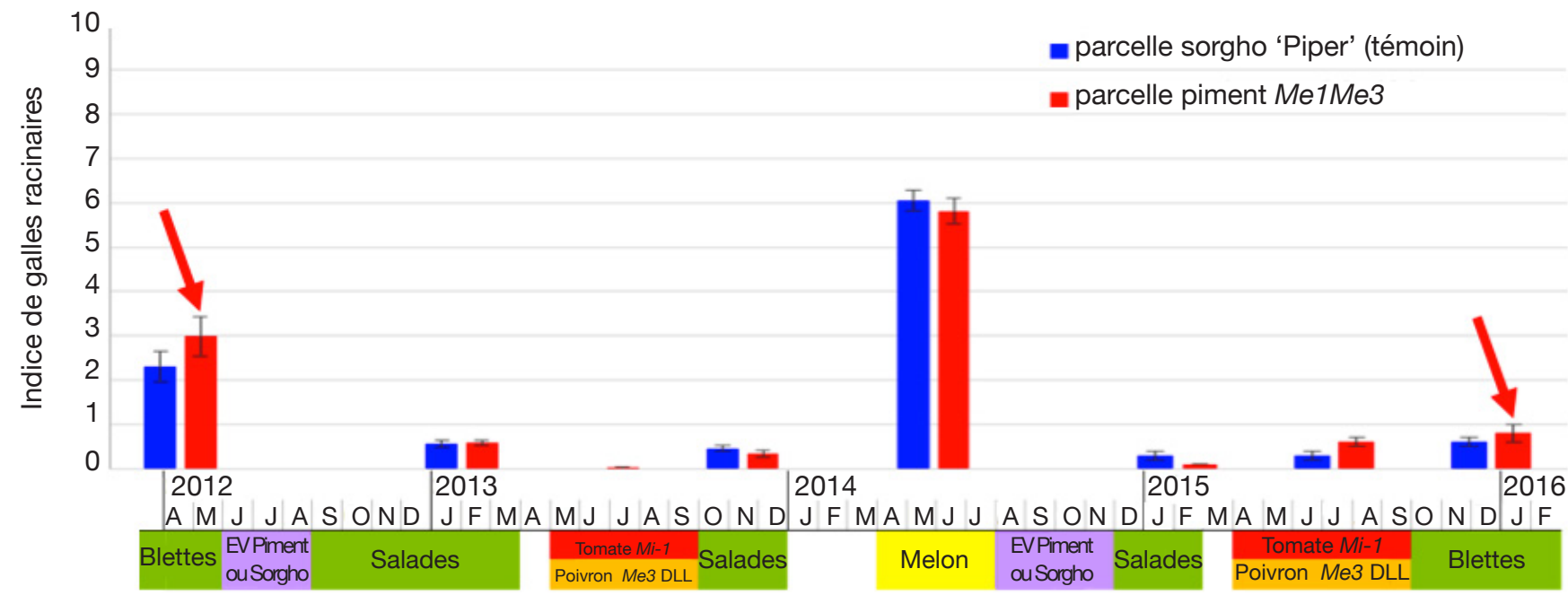

Figure 4. Sur le site de Six-Fours, effet du système S2 (engrais vert avec un piment-piège $M e 1 / M e 3$ des nématodes à galles combinant deux gènes de résistance, en été une année sur deux) sur l'indice de galles racinaires des différentes cultures : moyennes de 54 plants \pm erreur standard - Effect of system S2 (summer green manure: resistant hybrid pepper Me1/Me3) on gall index on root-knot nematodes-host plants of the crop rotation: means $(n=54) \pm$ standard deviation.

Les flèches montrent les IG initiaux et finaux sur blettes - arrows show the initial and final GI on chard; EV : engrais vert - green manure. 


\section{Cartographie racinaire}

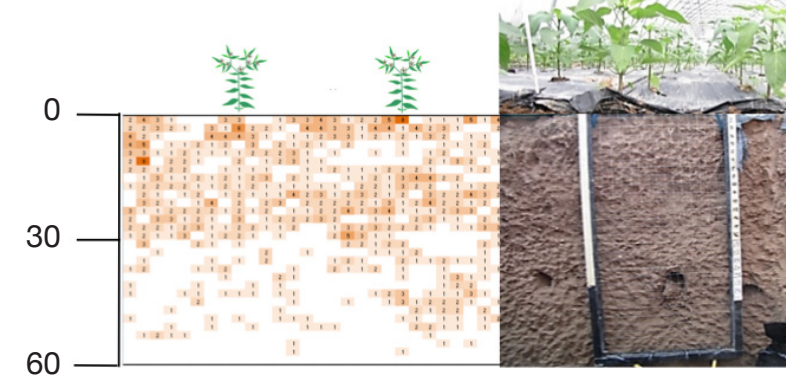

Code couleur du nombre de racine par cellule : 01223456

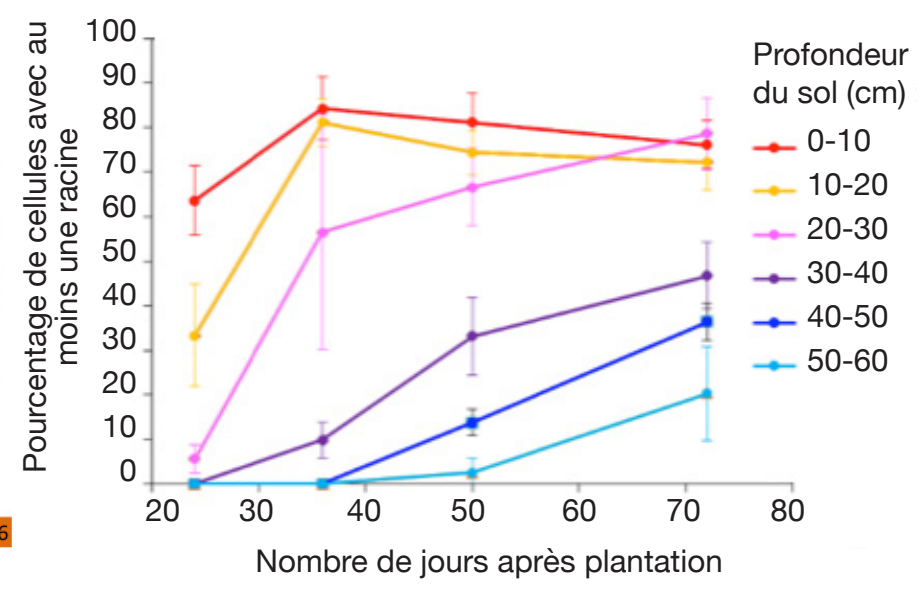

Figure 5. Sur le site d'Alénya, potentiel de colonisation du sol par les racines des piments résistants hybrides $M e 1 / M e 3$, plantés en mai 2013, avec une densité de plantation de 12 plants $\cdot \mathrm{m}^{-2}$. Les données donnent le pourcentage de cellules de $2 \times 2 \mathrm{~cm}$ avec au moins une racine : moyennes de 15 répétitions \pm erreur standard - Soil colonisation by the pepper Me $1 / \mathrm{Me} 3$ roots in the experimental station of Alénya, the peppers being planted on May 2013 at a density of 12 plants $\cdot m^{-2}$. The data indicate the percentage of $2 \times 2 \mathrm{~cm}$ cells of each layer containing at least one root: means $(n=15) \pm$ standard deviation (Chapuis, 2013).
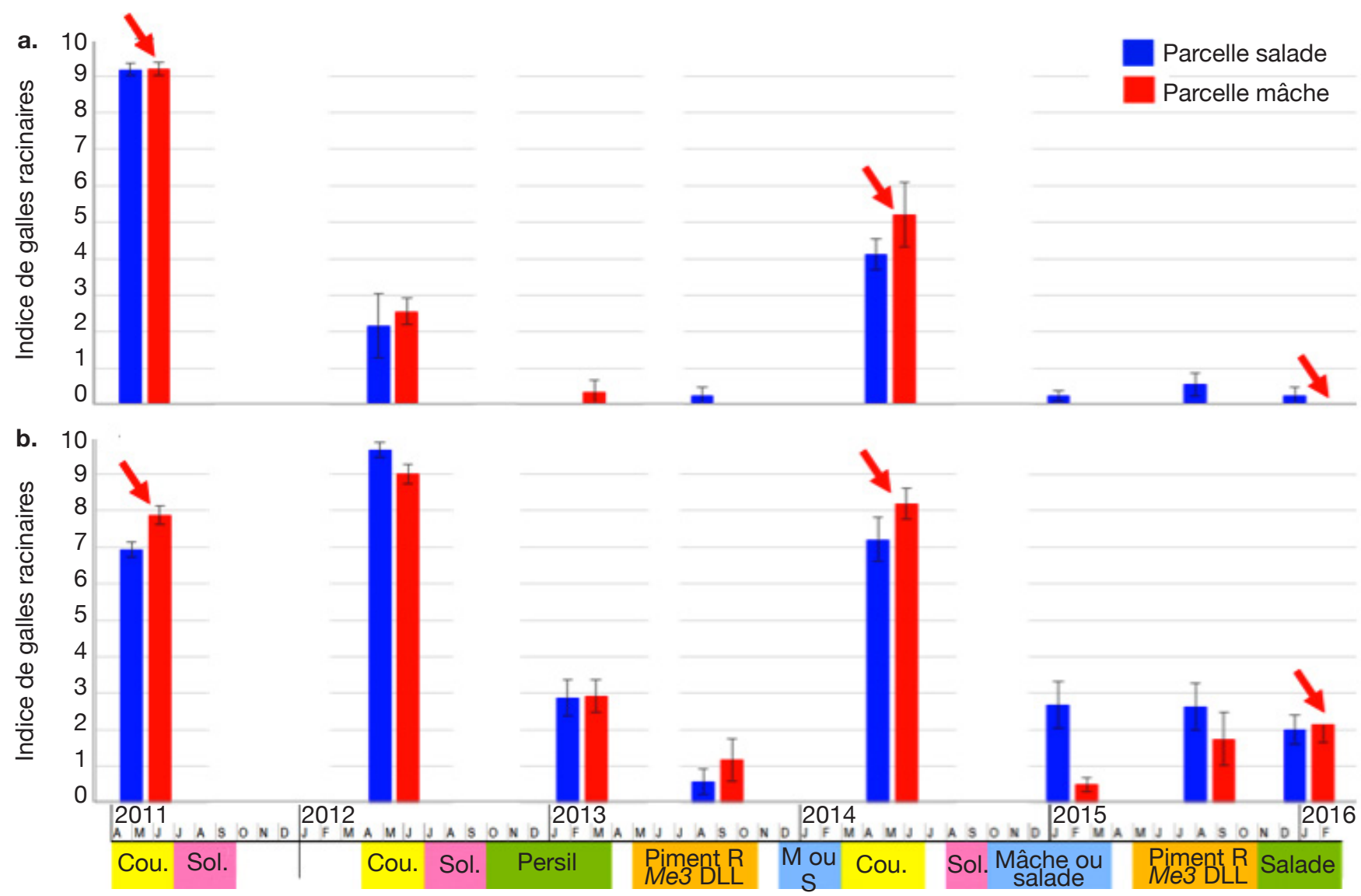

Figure 6. Sur le site de Marguerittes, effet du système S3 (augmentation de la diversité cultivée avec plante de coupure et solarisation en été une année sur deux) sur l'indice de galles racinaires des différentes cultures en fonction des rangs de plantation (a) rangs centraux, (b) rangs de bordure : moyennes de 30 répétitions \pm erreur standard - Effect of system S3 (increase of the cultivated diversity with non-host plant and solarization in summer one year on two) on the root gall index of different crops based on planting rows $(\boldsymbol{a})$ central ranks, $(\boldsymbol{b})$ border ranks: means $(n=30) \pm$ standard deviation.

Les flèches montrent les indices de galles initiaux et finaux sur courgette et salade - arrows show show the initial and final root gall index on zucchini and lettuce; Cou : courgette - zucchini; Sol. : solarisation - solarization. 
un enracinement correct, ce qui pourrait permettre de réduire les couts liés à cette technique. Par ailleurs, les piments $\mathrm{Me} 1 / \mathrm{Me} 3$ utilisés comme engrais verts ont produit une biomasse de $4,25 \mathrm{t} \cdot \mathrm{ha}^{-1}$ de matière sèche pour une densité de 12 plants $\cdot \mathrm{m}^{-2}$, ce qui est du même ordre de grandeur que le sorgho habituellement utilisé par les maraîchers.

En conclusion, bien que le piment $\mathrm{Mel} / \mathrm{Me} 3$ ait bien joué son rôle de piège des $\mathrm{NG}$, le prototype $\mathrm{S} 2$ n'a pas présenté une efficacité durable à long terme, sans doute parce que, sur ce site, les autres espèces phytoparasites étaient rares et n'ont pu jouer un rôle régulateur, contrairement à ce qui avait été observé sur le site d'expérimentation du prototype S1. Par ailleurs, la quantité de biomasse produite par le piment montre que le piment pourrait être utilisé non seulement pour piéger les nématodes à galles, mais aussi pour enrichir le sol en matière organique.

\subsection{Prototype S3, basé sur des cultures de coupure à l'automne et une solarisation bisannuelle en été}

Le site de Marguerittes était fortement contaminé (IG $>7$ sur la culture de courgette initiale). Les deux solarisations ont été efficaces pour protéger les rangs centraux des cultures de courgette suivantes $(\mathrm{IG}<3$, figure 6a) mais pas en bordure (IG $>8$, figure 6b). Les cultures d'hiver (salade et même la mâche, espèce peu sensible) ont été attaquées sur les rangs de bordure lorsqu'elles étaient plantées précocement en octobre. Les cultures de piment à résistance contournable ont été protégées par cette réduction de l'IS surtout sur les rangs centraux $(\mathrm{IG}<0,3)$. Ce phénomène de moindre efficacité de la solarisation en bordure de tunnel est régulièrement observé en parcelles de producteurs mais est encore mal expliqué (moindre étanchéité du paillage en bord de parcelle, recontamination par des racines d'adventices présentes à l'extérieur des tunnels, etc.).

Les autres espèces phytoparasites étaient rares dans ce système et leurs effectifs n'ont pas varié au cours de l'expérimentation. Les niveaux des populations de nématodes non phytoparasites ont augmenté après la culture d'été, aussi bien sur piment sensible que résistant et sur courgette (non figuré).

En conclusion, le prototype semble efficace pour contrôler les NG, à condition toutefois de s'assurer d'une meilleure efficacité de la solarisation en bordure de tunnel.

\section{4. Évaluation de l'acceptabilité des SDC}

Dans l'échantillon de 28 agriculteurs enquêtés, le degré d'acceptabilité des trois prototypes de SDC dépendait de deux ensembles de facteurs, d'une part le type d'exploitation (Figure 7a), d'autre part l'attitude des agriculteurs face aux changements techniques (Figure 7b). Il ressort des enquêtes une validation globale des critères qui avaient été pris en compte dans la phase de conception initiale, comme le créneau de commercialisation (présence/absence de débouchés pour valoriser les cultures non hôtes introduites dans la rotation) et la disponibilité des parcelles (disponibilité ou non pour introduire une interculture d'été nématicide).

- Le prototype S1 utilisant une variété de sorgho nématicide est bien accepté par une majorité d'agriculteurs, non seulement pour les exploitations cibles (commercialisant en circuit long et disposant de parcelles libres en été pour le sorgho) que pour les exploitations plus diversifiées. En effet, nombre d'entre eux cultivent déjà du sorgho en engrais vert et il ne s'agit que de changer de variété et de raccourcir le cycle de culture. Par contre, il n'est pas jugé acceptable sur les exploitations avec cultures longues, dont les parcelles ne sont pas libres en été.

- Le prototype S2 est jugé non acceptable par la majorité des agriculteurs à cause du cout actuel des semences hybrides de piment et du temps de plantation par rapport à leur référence (sorgho semé). - Le prototype S3 est jugé acceptable uniquement pour les exploitations diversifiées en circuit court, mais aussi par celles en circuit long mais en agriculture biologique, car ces maraîchers ont l'habitude de diversifier les rotations pour gérer la fertilité des sols et les bioagresseurs telluriques.

\section{DISCUSSION}

\subsection{Performance des prototypes pour le contrôle des NG}

Au bout de quatre ans d'évaluation en parcelles de producteurs, on constate une baisse significative de $90 \%$ des populations de Meloidogyne spp. après solarisation, engrais vert piment $M e 1 / M e 3$, sorgho biofumigant et même sorgho standard 'Piper', alors que ce dernier est réputé sans grande activité sur les NG. Des résultats controversés sont en effet décrits dans la littérature concernant l'efficacité des engrais verts sorghos vis-à-vis des NG (McSorley et al., 1994 ; Viaene \& Abawi, 1998 ; Wang et al., 2004 ; Collange et al., 2011). Les expérimentations en conditions contrôlées ont permis d'éclairer une partie de ces résultats et d'établir l'itinéraire technique le plus adapté à leur utilisation.

Pour le sorgho, on a montré l'existence conjointe de deux mécanismes de contrôle des NG (piégeage et biofumigation), avec un effet significatif du type de sol, de la durée de culture et du temps de biofumigation et une efficacité globale identique des deux sorghos s'ils sont 


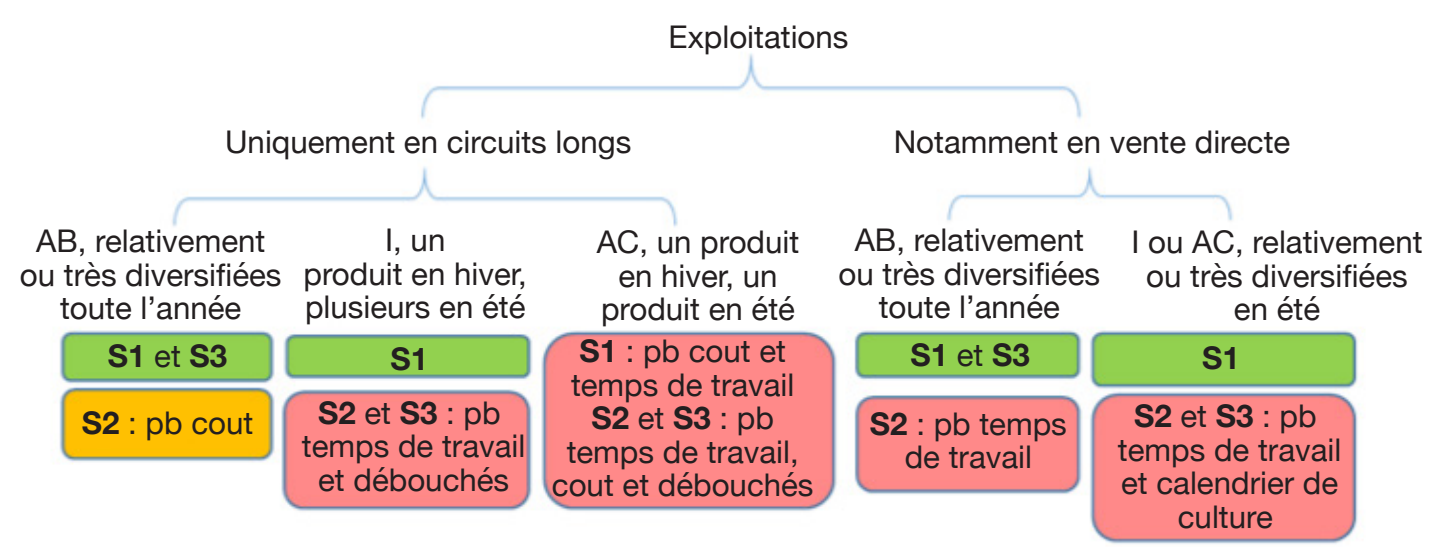

b

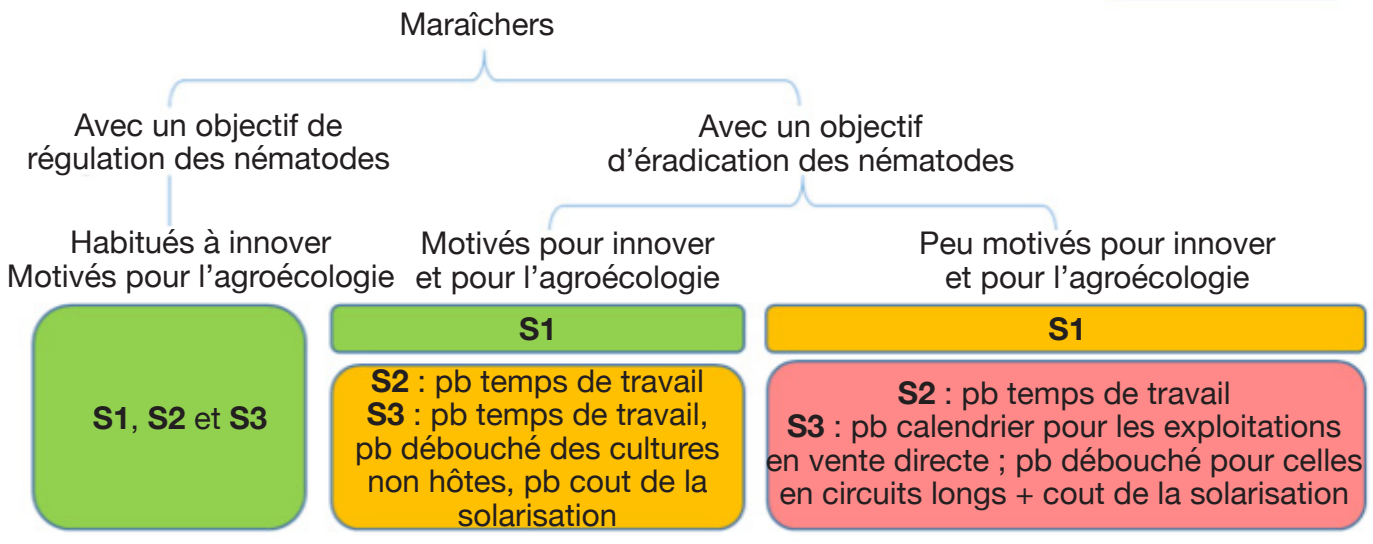

Figure 7. Évaluation par enquête de l'acceptabilité des systèmes de culture : (a) effet du type d'exploitation et (b) effet de la sensibilité des agriculteurs face au changement - Evaluation of the acceptability of cropping systems by survey: effect of the type of exploitation (a) and motivation of the farmers (b) (Furnion, 2014).

$\mathrm{AB}$ : pratiques certifiées Agriculture Biologique - certified organic farming practices; I : pratiques intermédiaires, incluant des principes relevant de l'agroécologie - intermediate practices, including principles of agroecology; AC : pratiques en agriculture conventionnelle - practices in conventional agriculture; S1, S2, S3 : voir tableau 1 - see table 1; vert - green: acceptable - high acceptability ; orange : moyennement acceptable — middle acceptability ; rouge — red : plutôt inacceptable — low acceptability ; pb : problème - problem.

enfouis après quatre semaines, du fait des phénomènes de compensation. Par contre, une culture plus longue (6-10 semaines), comme le font généralement les maraîchers, entraine une multiplication des NG. Il est donc très important d'enfouir les sorghos quatre semaines après semis, soit au stade quatre feuilles, pour maximiser la production de dhurrine (plus importante lorsque la plante est jeune) et pour éviter que le cycle du nématode ne s'accomplisse (5-6 semaines à $\left.25^{\circ} \mathrm{C}\right)$ : on favorisera ainsi les deux modes d'action des sorghos, biofumigation et piégeage.

Pour le piment $\mathrm{Me} 1 / \mathrm{Me} 3$ cultivé en engrais vert piège, le bon potentiel de colonisation du sol par ses racines, son niveau de résistance fort, durable, stable à haute température et son efficacité comme plante-piège ouvrent des perspectives d'innovation intéressantes pour le contrôle des NG. Des améliorations doivent encore être réalisées : diminuer la densité de culture et faire un semis direct afin de minimiser les couts ; adapter l'itinéraire technique pour optimiser l'explora- tion racinaire ; sélectionner des lignées fixées homozygotes $\mathrm{Mel} / \mathrm{Me} 3$ pour réduire le cout de production des semences.

Cependant, malgré les baisses conséquentes de population de Meloidogyne dans le sol, on constate une forte fluctuation des dégâts dans l'espace (pour la solarisation) et dans le temps (suivant les cultures). En effet, si les populations de NG sont réduites après une technique donnée, une faible population résiduelle suffit à recontaminer le sol dès qu'une espèce sensible est cultivée pendant la période d'activité des nématodes, sans toutefois atteindre le niveau initial.

\subsection{Durabilité des résistances}

Les résultats indiquent une très bonne protection des piments sur porte-greffe résistant Me3-DLL et des tomates résistantes $M i-1.2$ lorsque les populations de Meloidogyne spp. sont fortement réduites par les engrais verts (piments ou sorghos) ou la solarisation. 
On note des contournements lorsque les populations sont peu réduites avec développement de nématodes virulents sur quelques piments, par exemple sur les rangs de bordure du site S3, moins désinfectés par la solarisation. Ces précédents pouvant influencer le cycle du parasite d'un point de vue quantitatif (IS) et qualitatif (apparition de populations virulentes), ils apparaissent donc comme un levier déterminant pour accroitre la durabilité des résistances variétales.

\subsection{Dynamique de la nématofaune du sol}

Les SDC les plus efficaces contre les NG semblent être ceux où la nématofaune était la plus diversifiée et abondante, ce qui pourrait être dû à un effet de compétition comme suggéré par Ferris et al. (2001) et Nahar et al. (2006). Sur le site de Lambesc où la communauté de nématodes était très riche, on observe que seuls les Telotylenchidae se sont multipliés suite aux sorghos puis la population s'est réduite, quelle que soit la culture mise en place. Divers auteurs ont également signalé un effet négatif ou au contraire multiplicateur des sorghos selon les genres de nématodes phytoparasites (McSorley \& Dickson, 1995 ; Crow et al., 2001 ; LaMondia et al., 2002 ; Asmus et al., 2008). Les populations de nématodes non phytoparasites se sont également multipliées tout au long de l'expérimentation, sans aucun effet négatif des engrais verts ou des cultures d'été résistantes. Comme ce sont des indicateurs de santé des sols (Yeates et al., 1994), leur augmentation est donc très encourageante.

\subsection{Approche système et innovations}

Pour favoriser la durabilité des résistances et la gestion des bioagresseurs, la démarche système et participative a permis de concevoir entre chercheurs, expérimentateurs et conseillers techniques plusieurs prototypes, une gamme d'innovations adaptées à des types d'exploitations spécifiques. L'enquête a permis de valider la plupart des contraintes qui avaient été prises en compte dans la conception initiale. Le prototype à base de sorgho nématicide relève de la substitution au sens de Hill \& McRae (1995) (changement de variété de sorgho et raccourcissement du cycle de culture) et a donc plus de chance d'être adopté par un nombre conséquent de maraîchers (Goillon et al., 2016). Par contre, le prototype basé sur l'utilisation de piment piège en engrais vert est une innovation radicale, qui a nécessité de concevoir un itinéraire technique spécifique pour optimiser le piégeage des NG. Difficile à mettre en œuvre et trop couteux aujourd'hui pour être adopté, si ce n'est par des maraîchers innovants et intéressés par les pratiques agroécologiques, il a cependant le mérite de ré-ouvrir le champ des possibles (Meynard et al., 2012 ; Navarrete et al., 2016). Le travail d'enquête indique également des pistes pour l'adaptation des SDC et le choix des innovations à développer : il apparait nécessaire de concevoir des SDC adaptés aux exploitations en circuits longs et cultivant des cultures d'été longues, qui ne peuvent ni diversifier leurs cultures (prototype S3), ni introduire des engrais verts en été (prototypes S1 et S2).

\section{CONCLUSIONS ET PERSPECTIVES}

Le projet GeDuNem a permis de concevoir et d'évaluer les performances de SDC agroécologiques répondant aux attentes des producteurs et à des enjeux de la filière, mais aussi d'approfondir les connaissances sur le fonctionnement écologique de ces systèmes. L'interdisciplinarité entre généticiens, pathologistes, nématologistes et agronomes a permis de réfléchir à la fois aux dimensions biologiques et humaines des innovations, de produire ensemble de nouveaux objets (e.g. une interculture avec variété de piment résistant pour piéger les NG du sol). Des trous de connaissances sur certains leviers agroécologiques ont été identifiés, ce qui ouvre de nouvelles questions de recherche. Plusieurs perspectives sont envisagées :

- améliorer l'efficacité des prototypes par de nouvelles expérimentations, afin de repérer d'éventuels effets cumulatifs à long-terme des pratiques mises en place,

- simuler par modélisation sur des temps longs la dynamique d'infection des racines par les nématodes en fonction des différentes stratégies de déploiement des gènes de résistance et ainsi déterminer les stratégies optimales de déploiement des plantes résistantes,

- simplifier les prototypes et réduire les couts pour qu'ils puissent être plus facilement mis en œuvre par les agriculteurs,

- identifier de nouveaux leviers techniques pour accroitre les performances ou la durabilité des SDC en tenant compte des compétitions interspécifiques entre nématodes,

- élargir le questionnement à d'autres pathogènes telluriques et prendre en compte plus largement les communautés microbiennes et l'état des sols.

\section{Abréviations}

IG : indice de galles

IS : taux d'infestation

J2 : juvéniles

MO : masse d'œufs

$\mathrm{NG}$ : nématodes à galles

NNP : nématodes non phytoparasites

NPP : nématodes phytoparasites 
SDC : système de culture

VIF : film imperméable

\section{Remerciements}

Ces recherches ont bénéficié du soutien financier de la société UPL France pour les expérimentations en conditions contrôlées (2014-2015), du métaprogramme INRA SMaCHSustainable Management of Crop Health (action Presume) pour le projet «GeDuNem»(2012-2016) et du label du GIS PICLeg. Les auteurs remercient les partenaires et les professionnels agricoles qui ont permis la réalisation de ces études.

\section{Bibliographie}

Asmus G.L., Inomoto M.M. \& Cargnin R.A., 2008. Cover crops for reniform nematode suppression in cotton: greenhouse and field evaluations. Trop. Plant Pathol., 23, 85-89.

Barbary A. et al., 2014. The plant genetic background affects the efficiency of the pepper major nematode resistance genes Mel and Me3. Theor. Appl. Genet., 127, 499-507.

Brun H. et al., 2010. Quantitative resistance increases the durability of qualitative resistance to Leptosphaeria maculans in Brassica napus. New Phytol., 185, 285-299.

Byrd D.W., Kirkpatrick T. \& Barker K.R., 1983. An improved technique for clearing and staining plant tissues for detection of nematodes. J. Nematol., 15, 142143.

Castagnone-Sereno P., 2002. Genetic variability in parthenogenetic root-knot nematodes, Meloidogyne spp., and their ability to overcome plant resistance genes. Nematology, 4, 605-608.

Chapuis M., 2012. Test de la faisabilité de prototypes de systèmes de culture intégrant des techniques alternatives. Enquêtes auprès des producteurs. Mémoire : AgroParisTech, Paris (France).

Collange B. et al., 2011. Root -knot nematode (Meloidogyne) management in vegetable crop production: the challenge of an agronomic system analysis. Crop Prot., 30(10), 1251-1262.

Collange B. et al., 2014. Alternative cropping systems can have contrasting effects on various soil-borne diseases: relevance of a systemic analysis in vegetable cropping systems. Crop Prot., 55, 7-15.

Crow W.T., Weingartner D.P., Dickson D.W.\& McSorley R., 2001. Effect of sorghum-sudangrass and velvetbean cover crops on plant-parasitic nematodes associated with potato production in Florida. J. Nematol., 33(4S), 285-288.

Djian-Caporalino C., 2012. Root-knot nematodes (Meloidogyne spp.), a growing problem in French vegetable crops. EPPO Bull., 42(1), 127-137.

Djian-Caporalino C. et al., 2014. Pyramiding, alternating or mixing: comparative performances of deployment strategies of nematode resistance genes to promote plant resistance efficiency and durability. BMC Plant Biol., 14, 53-66.

Djian-Caporalino C. et al., 2015. Le projet GeDuNem : innovations techniques et variétales pour une gestion durable et intégrée des nématodes à galles dans les systèmes maraîchers sous abris. In : Actes de la $5^{\grave{~}}$ Conférence internationale sur les Méthodes alternatives de Protection des Plantes, 11-13/03/2015, AFPP (Association Française de Protection des Plantes), Lille, France.

Evans T.A. et al., 2007. Management of Xiphinema americanum and soybean severe stunt in soybean using crop rotation. Plant Dis., 91, 216-219.

Ferris H., Bongers T. \& de Goede R.G.M., 2001. A framework for soil food web diagnostics: extension of the nematode faunal analysis concept. Appl. Soil Ecol., 18, 13-29.

Furnion C., 2014. Assessing the acceptability of alternative cropping systems limiting the pressure of root-knot nematodes. Mémoire: ISARA/Wageningen, Lyon (France).

Goillon C. et al., 2016. Utiliser le sorgho pour lutter contre les nématodes à galles. Phytoma, 698, 39-44.

Havard M. et al., 2017. Guide de l'expérimentateur système : concevoir, conduire et valoriser une expérimentation "système » pour les cultures assolées et pérennes. GIS PIClég, GIS Fruits, Réseau ECOVITI, RMT Systèmes de culture innovants, GIS Relance Agronomique.

Hill S. \& McRae R., 1995. Conceptual frameworks for the transition from conventional to sustainable agriculture. J. Sustainable Agric., 7, 81-87.

Jones J.T. et al., 2013. Top 10 plant-parasitic nematodes in molecular plant pathology. Mol. Plant Pathol., 14, 946961.

LaMondia J.A., Elmer W.H., Mervosh T.L. \& Cowles R.S., 2002. Integrated management of strawberry pests by rotation and intercropping. Crop Prot., 21, 837-846.

Loyce C. et al., 2008. Interaction between cultivar and crop management effects on winter wheat diseases, lodging, and yield. Crop Prot., 27, 1131-1142.

McSorley R., Dickson D.W., Debrito J.A. \& Hochmuth R.C., 1994. Tropical rotation crops influence nematode densities and vegetable yields. J. Nematol., 26(3), 308-314.

McSorley R. \& Dickson D.W., 1995. Effect of tropical rotation crops on Meloidogyne incognita and other plant-parasitic nematodes. J. Nematol., 27(4S), 535-544.

Meynard J.M., Doré T. \& Lucas P., 2003. Agronomic approach: cropping systems and plant diseases. C.R. Biol., 326, 37-46.

Meynard J.M., Dedieu B. \& Bos A.P., 2012. Re-design and co-design of farming systems. An overview of methods and practices. In: Darnhofer I., Gibon D. \& Dedieu B., eds. Farming systems research into the $21^{\text {st }}$ century: the new dynamic. Springer, 407-432. 
Nahar M.S. et al., 2006. Differential effects of raw and composted manure on nematode community, and its indicative value for soil microbial, physical and chemical properties. Appl. Soil Ecol., 34, 140-151.

Navarrete M. et al., 2010. Elaborating innovative solutions with experts using a multicriteria evaluation tool. The case of soilborne disease control in market-gardening cropping systems. In: Proceedings of the International symposium "Innovation and Sustainable Development in Agriculture and food", June 28-July 1, 2010, Montpellier, France.

Navarrete M. et al., 2016. A resistant pepper used as a trap cover crop in vegetable production strongly decreases root-knot nematode infestation in soil. Agron. Sustainable Dev., 36, 68-.

Navarrete M. et al., 2017. Concevoir et évaluer avec les acteurs des systèmes de culture adaptés à leurs cadres de contraintes et d'objectifs en production maraichère sous abri. Mise en pratique et enseignements dans les projets GeDuNem et 4SYSLEG. Innovations Agron., 61, 33-49.

Reau R. et al., 2012. Les ateliers de conception de systèmes de culture pour construire, évaluer et identifier des prototypes prometteurs. Innovations Agron., 20, 5-33.

Roberts P.A., Dalmasso A., Cap G.B. \& CastagnoneSereno P., 1990. Resistance in Lycopersicon peruvianum to isolates of $\mathrm{Mi}$ gene-compatible Meloidogyne populations. J. Nematol., 22, 585-589.

Seinhorst J.W., 1962. Extraction methods for nematodes inhabiting soil. In: Murphy P.W., ed. Progress in soil zoology. London: Butterworths, 243-256.

Viaene N.M. \& Abawi G.S., 1998. Management of Meloidogyne hapla on lettuce in organic soil with sudangrass as a cover crop. Plant Dis., 82, 945-952.

Villeneuve F., Djian-Caporalino C. \& Szilvasi S., 2013. Les nématodes et les cultures légumières. Biologie et contexte réglementaire (1 ère partie). Infos CTIFL, 289, 41-50

Wang K.H., McSorley R. \& Gallaher R.N., 2004. Winter cover crops and nematode densities. J. Nematol., 36(4), 517-523.

Yeates G.W., 2003. Nematodes as soil indicators: functional and biodiversity aspects. Biol. Fertil. Soils, 37, 199-210.

Zeck W.M., 1971. A rating scheme for field evaluation of root-knot nematode infestations. PflanzenschutzNachrichten, 24, 141-144.

(37 réf.) 